Article

\title{
Are the Greenhouse Gas Implications of New Residential Developments Understood Wrongly?
}

\author{
Jukka Heinonen $^{1, *}$, Antti-Juhani Säynäjoki ${ }^{1}$, Matti Kuronen ${ }^{2}$ and Seppo Junnila ${ }^{1}$ \\ 1 Department of Surveying and Planning, School of Engineering, Aalto University, P.O. Box 15800, \\ Aalto 00076, Finland; E-Mails: antti.saynajoki@aalto.fi (A.-J.S.); seppo.junnila@aalto.fi (S.J.) \\ 2 RAKLI-The Finnish Association of Building Owners and Construction Clients, Annankatu 24, \\ Helsinki 00100, Finland; E-Mail: matti.kuronen@rakli.fi \\ * Author to whom correspondence should be addressed; E-Mail: jukka.heinonen@aalto.fi; \\ Tel.: +358-50-577-1831.
}

Received: 1 June 2012; in revised form: 26 July 2012 / Accepted: 27 July 2012 /

Published: 6 August 2012

\begin{abstract}
Built environment carbon reduction strategies materialize predominantly in city-level greenhouse gas (GHG) management, where new residential development appears as one of the key instruments. However, city-level assessments are often incapable of producing data at a community or neighborhood level and thus they may heavily underestimate the emissions from new construction. This paper explores the implications of low-energy residential construction as an instrument of climate change mitigation in the built environment and demonstrates why city-level approaches easily fail to identify the significance of the emissions from construction. We employ a hybrid life cycle assessment (LCA) approach to demonstrate that, when the temporal allocation of emissions from the construction and use phases is taken into account, construction phase emissions come to have a central role in finding effective GHG mitigation strategies - even when the emissions from all consumption activities during the use phase are included in the assessment. In fact, their role would seem to be so central that new residential construction cannot be utilized as an instrument of city carbon management, even over a relatively long period. While we analyze a case study from Finland, the analysis intends to highlight the situation throughout the globe.
\end{abstract}

Keywords: life cycle assessment; climate change; city; neighborhood; construction; low-energy; resident 


\section{Introduction}

Major greenhouse gas $(\mathrm{GHG})$ reductions are needed right now to reach the globally set target of limiting the global temperature rise to $2.0{ }^{\circ} \mathrm{C}$. This target can only be achieved if two conditions are met. First, before 2050 the overall reduction would need to fall between $50 \%$ and $85 \%$ relative to the 2000 level. However, the first condition only applies if the second condition is met, namely, that the peaking year of cumulative global emissions must occur between 2010 and 2015. Even a $2.4-2.8{ }^{\circ} \mathrm{C}$ rise in the level of the average global temperature would require a reduction of $30 \%-60 \%$ in $\mathrm{GHG}$ emissions before 2050, the peaking year being before 2020 [1]. Even reaching this lower level is a huge challenge for the coming years.

The built environment will be in a central role in the creation of mitigation strategies reaching for these goals. With ever-growing numbers of people residing in cities, and cities already being accountable for the vast majority of global GHG emissions [2], built environment carbon reduction strategies will predominantly take place through city-level carbon management. Embracing this role, cities worldwide have already set targets for reducing their carbon loads. City-level GHG assessment methods have been extensively studied in recent years and many techniques have been developed [3-7]. However, the concept of city carbon management is still very problematic since the city-level assessment methods may be incapable of producing information on phenomena occurring at a community or neighborhood level within cities. Thus, current practices to guide low-carbon development might be incomplete, leading to actions with unknown and potentially even unwanted results.

In this paper we try to create a better understanding of the problems related to low-energy residential construction, typically one of the key strategies of city-level carbon management [8,9]. We demonstrate the differences in the assessment results when the perspective is changed from the city level to the new residential development level with a projection of the future use phase emissions. To create a better understanding of the significance of the construction phase emissions in new residential developments, we take the full carbon footprint of the residents into account throughout the analysis.

Currently, while a lot of policy focus has been put on increasing building energy efficiency, the construction phase emissions, including those embedded in the materials and production chains, have been predominantly ignored (e.g., [10-12]). This is probably due to traditional LCAs of building GHG emissions showing the use phase to dominate the emissions - with a share of 90 percent $[13,14]$. However, as energy efficiency increases, the construction phase accounts for more and more (up to over $50 \%$ ) of the overall life cycle GHG emissions [15], leaving a large share of the building related GHGs outside of the policy focus [11]. Furthermore, the current city-level assessment models may not even be capable of producing the necessary information for managing the planning process of low-carbon city development due to underestimating the effects of construction on the city-level GHGs [16,17], as this study will demonstrate. This is due to one key reason. On the city scale, the GHG emissions related to residential construction seem small compared to the operating emissions of existing buildings since the renewal rate of the building stock is low. However, the situation may be totally different when a single residential development is examined and the temporal allocation of the emissions is taken into account. Then the construction phase emissions seem to dominate for decades and the operation of the building has only secondary importance, even when all the GHG emissions of the residents are taken into account. 
It is obvious that all new construction leads to GHG emissions, and thus construction as such can never be about GHG mitigation. However, increasing building energy efficiency is one GHG mitigation strategy [8,9], and the construction phase emissions are inevitably an integral part of the buildings' life cycle emissions. In addition, in Finland and also globally, significant migration from rural areas to cities is taking place, leading to a huge need for new residential construction. Thus, increasing understanding of the impacts of the GHG emissions occurring during major development projects on consumer carbon footprints is very important. For example, considering the above-mentioned time limits of current GHG mitigation targets for reducing GHG emissions, this study demonstrates that regardless of the energy efficiency level of the buildings, new construction cannot be utilized as a means to achieve these targets. Building energy efficiency can be argued to be important, and when new construction takes place the study recommends aiming for high energy efficiency, but it should be understood that, from the climate change perspective, the gains only materialize after decades if the carbon spike from construction remains at the level found in this study.

The paper builds understanding of the role of the construction phase emissions in the residents' carbon footprints by assessing the life cycle GHG emissions of a new residential development in Espoo, Finland. The assessment is conducted with a LCA framework capable of including all emissions from the construction phase and, later, those from all the consumption of the projected future residents, as well as distinguishing the temporal allocation of the emissions. The functional unit is throughout the paper the inhabitant, i.e., the consumer. With this choice, the results from the different life cycle phases can be compared, which has not been possible with many previous studies. This type of approach also places the emissions from different activities, and taking place at different moments, in their true context and gives perspective on the relative importance of different emission sources, which, the study argues, is an important precondition for effective city carbon management. To demonstrate how city-level assessments may easily fail to produce reliable information to guide low-carbon city development, we present the city-level assessment results and the new residential development assessment results concurrently. While we employ a case study from Finland, the analysis tries to highlight the situation throughout developed countries.

The structure of the remainder of the paper is as follows: in Section 2 the case is presented, in Section 3 the assumed future residents are profiled, Section 4 presents the assessment frameworks and the data utilized, Section 5 goes through the assessment results, Section 6 discusses the global representativeness of the case area, and finally Section 7 discusses the findings and limitations as well as creates a wider context for the study.

\section{The Case Residential Area}

The study exploits a new residential development project in Espoo, in the Helsinki Metropolitan Area (HMA) in Finland. The permitted building volume for the area is about 35,000 sq. m. The area, currently under construction, is projected to accommodate 550 residents in terraced houses, semi-detached houses and detached houses. The cost of the construction of the area is estimated by the developer company to be 77 million Euros (M€). In the study, it is assumed that the residential buildings comply with the National Building Code of Finland (NBC) 2010 regarding energy efficiency, which sets the limit at $100 \mathrm{kWh} / \mathrm{sq}$. m for total energy use of which $65 \mathrm{kWh} / \mathrm{sq}$. $\mathrm{m}$ is for 
heating [10]. The limits result in approximately 55\% higher energy efficiency than the average of the existing residential building stock. Table 1 gathers some of the important figures related to the area.

Table 1. Characteristic features of the case area.

\begin{tabular}{ll}
\hline Characteristic & Description \\
\hline Site & Residential development area in Espoo, Finland \\
Size of the site & 54 ha \\
Ownership & Privately owned land \\
Permitted building volume & 35,000 sq. m \\
Number of apartments & 220 \\
Building types & Terraced, semi-detached and detached houses \\
Current situation of the area & Under construction \\
Construction costs, of which: & 77 M€ (estimated) \\
$\quad$ Residential buildings & 70 M€ \\
Infrastructure & $7 \mathrm{M} €$ \\
Building energy efficiency & 2010 National Building Code \\
Projected number of residents & 550 \\
\hline
\end{tabular}

A 25-year lifespan is covered in the study. This time frame was adopted as it is a long enough period to demonstrate the GHG impact of the area compared to the near future GHG reduction targets, and no major renovations are supposed to take place during the first 25 years, which would significantly alter the construction related GHG emissions [18]. While the buildings' life cycle is considerably longer, in Finnish conditions major refurbishments start after around a 30-year lifespan and bring about new, though presumably smaller, GHG spikes. A longer perspective in the study would just significantly increase the uncertainties related to the use phase assessment and would not help to explain the major findings. During a longer time span radical changes in both the consumption patterns as well as in production technologies will take place, meaning that the use phase emissions, if not totally altered, will at least consist of different sources.

\section{The Future Residents}

As the residential area is still under development, assumptions about the future residents were necessary for the GHG assessments. Judging by the building types, the number of apartments in the area, and the projected number of residents, we assumed the area would attract similar residents to those who currently reside in similar buildings in Espoo. This assumption, that similar areas within a city attracting similar residents, is supported by the findings of Majamaa et al. [19]. The residents in similar terraced, detached and semi-detached houses in Espoo are affluent families with a high income and a high consumption volume. Given this assumption, and the data on the area in Table 1, we created a profile resident for the area.

The consumption profile of an average terraced, detached and semi-detached house resident of Espoo is taken from the Consumption Survey 2006 of Statistics Finland [20], which presents the annual purchases of an average consumer in a very detailed form with approximately 1000 consumption categories. Two important amendments to the average profile were made to bind the profile to the projected residential area. Firstly, that the housing energy consumption of the residents complies with 
the new NBC, meaning an approximately 55\% reduction in the average energy purchases compared to the average in Espoo. Secondly, that the share of housing payments covering the price of the residence was removed, as the GHG emissions related to the building are covered already in the construction phase GHG assessment of the area.

The annual per capita net income of the average terraced, detached or semi-detached house resident in Espoo is 34,500 $€$ and the consumption volume 21,200 $€[20]$. To put the figures in context, the respective average income in Finland is $16,800 €$ and annual consumption is 14,300 $€$ [20], well below the levels above. However, when the housing payments and reduced energy consumption (altogether $4,900 €)$ are removed from the annual consumption, the remaining consumption volume of the profile resident is $16,300 €$. Table 2 comprises the important information on the profile resident.

Table 2. The key characteristics of the profile resident of the case area.

\begin{tabular}{lc}
\hline Characteristics of the projected residents & Amount \\
\hline Family size & $\sim 2.5$ \\
Annual disposable income (per capita) & $34,500 €$ \\
Annual consumption & $21,200 €$ \\
Enhanced consumption (without housing payments and with reduced energy costs) & $16,300 €$ \\
\hline
\end{tabular}

\section{The GHG Assessment Frameworks}

The GHG emissions of the case residential area, within the scope of the study, consist of the construction phase GHGs and the use phase GHGs within the 25-year time span. Concerning both phases, the life cycle GHGs of all the goods and services utilized for the construction and maintenance of the area, as well as those consumed by the residents, are included in the assessment. As mentioned already in the introduction, the functional unit in the assessments is throughout the paper the inhabitant, meaning the average projected future resident (described in the previous section) living in an average residence in the new residential area for the 25-year lifespan. This enables comparisons between the emissions related to different life cycles as well as drawing meaningful policy implications. Both models are developed by the authors and have been utilized in previous studies and published recently in several academic journals [16,17,21-24].

The models utilize input-output (IO) based hybrid LCA approaches that are especially suitable for larger system level assessments [25], as conducted in this study. In general, hybrid approaches aim at avoiding the problems and taking advantage of the best qualities of the two main approaches to conducting an LCA, process LCA, and IO LCA. Process analyses, while potentially very accurate, would be tremendously laborious to conduct on a large system level. In addition, process LCAs inherently suffer from a truncation error of the boundary selection that may lead to underestimations of the environmental impacts [26]. IO LCAs, often based on environmentally extended IO matrices of the national accounts of a certain economy, provide full coverage in the included production and delivery chain emissions; the IO basis of the utilized assessment models thus helping to avoid the truncation error. Process data is added to both models to take into account the most important local emission factors. Detailed descriptions of the models and the methods in general, as well as profound discussions on the qualities of the models, may be found in the above-mentioned papers, whereas only the most important qualities are described here. The data sources employed are also presented below. 


\subsection{The Use Phase GHG Assessment Framework}

To include comprehensively the production and supply chain emissions of the consumed goods in the assessment, the assessment model employed is based on the tiered hybrid LCA method [25,26], which means that even in the sectors where process data is utilized, the comprehensiveness is maintained by assessing the production and delivery chain emissions with the IO matrices.

The model exploits the output tables of the Carnegie-Mellon University Economic Input-Output LCA (EIO-LCA) 2002 model [27] to create a WRI Scope 3 [28] perspective on the GHG emissions related to living. The GHGs included in the assessment model are $\mathrm{CO}_{2}, \mathrm{CH}_{4}, \mathrm{~N}_{2} \mathrm{O}$ and $\mathrm{HFC} / \mathrm{PFCs}$. Despite the limitations, an IO approach is able to capture an infinite number of transactions in the upstream production chains related to all goods [25]. Not suffering from the truncation error, the method is very useful in analyzing complex systems such as overall consumption. Lenzen et al. have argued that the most disaggregated model should be employed due to the significant impact on the results of the aggregation level [29]. In line with this, a US economy based model was selected since, as the most disaggregated model available, it provided the best fit with the input data.

A model based on a foreign economy inherently includes sources of bias from temporal fluctuation in currency rates, differences in regional and between-sectors inflation, and differences in industry structures. To take the inflation and currency rate fluctuations into account, the output tables were corrected with a purchasing power parity (PPP) multiplier [30], a method utilized earlier i.e., by Weber and Matthews [31]. Also, over 50\% of the value of goods consumed in Finland is oriented to imports [32], which strongly supports the utilization of this type of hybrid model. Furthermore, the model has been demonstrated to describe the Finnish economy reliably when enhanced with local data as described below [5].

To increase the reliability of the model, the tiered hybrid method is utilized to incorporate local emissions data into the assessment. The local aspects include combustion phase emissions of the local combined heat and power (CHP) plant [33] that is assumed to produce the energy for the area, fuel combustion emissions of private driving in Finland [34] and Finnish life cycle emissions data on public transport [35] (approximately a 30\% share of the overall emissions). In addition, a regional price level correction factor is employed to avoid bias from housing price level variations.

The input data source exploited is the 2006 consumption survey of Statistics Finland [20]. The survey presents the annual purchases of different goods and services of the profile resident. The survey includes approximately 1000 categories of goods and services, thus depicting consumption in very high detail. To fit the data with the EIO-LCA sectors, these categories were aggregated to 59 and broadened further to five broad consumption areas for presentation purposes. Table 3 presents the monetary inputs of the projected profile resident in the five areas, together with the employed data sources.

Of the five consumption areas, "Housing" comprises emissions from annual maintenance and refurbishments, water and waste water, waste management and cleaning, home appliances, furniture, and all energy associated with housing (private and communal heat and electricity). "Ground transport" comprises the emissions from all activities related to private driving, purchase and maintenance of the vehicles, and public ground transport. "Tangible goods" include food and beverages along with the consumption of durable goods such as clothes, sports equipment, and home electronics. "Services" 
mostly puts together inputs from leisure services such as cultural events, sports and leisure facilities, hotels, restaurants, beauty services, and communication services. Health, nursing and training services are also included in this category, but only form a minor share of the emissions since these are heavily publicly subsidized services in Finland and only the monetary transactions are included in the input data. "Air, maritime and package travel", including package holidays, were separated into their own category due to their distinct nature compared to ground transport.

Table 3. The five broad consumption areas, the input data sources, the volume of the annual purchases of the profile resident, and the output data sources.

\begin{tabular}{|c|c|c|c|c|}
\hline $\begin{array}{l}\text { Consumption } \\
\text { area }\end{array}$ & Input source & $\begin{array}{l}\text { Amount } \\
(€)\end{array}$ & Output source & $\begin{array}{l}\text { Local emissions factors } \\
\left(\mathrm{CO}_{2}\right)\end{array}$ \\
\hline Housing & Consumer survey 2006 & 2,300 & $\begin{array}{l}\text { Energy fuel combustion: } \\
\text { local power plant } \mathrm{CO}_{2} \\
\text { The rest, EIO-LCA }\end{array}$ & $\begin{array}{l}339 \mathrm{~g} / \mathrm{kWh} \text { for electricity, } \\
305 \mathrm{~g} / \mathrm{kWh} \text { for heat }[33]\end{array}$ \\
\hline \multirow{4}{*}{ Ground transport } & \multirow{4}{*}{ Consumer survey 2006} & \multirow{4}{*}{2,500} & $\begin{array}{l}\text { Private driving fuel } \\
\text { combustion: Motiva }\end{array}$ & $\begin{array}{l}95 \text { octane gasoline } 2.35 \mathrm{~kg} / \mathrm{L} \text {, } \\
\text { diesel } 2.66 \mathrm{~kg} / \mathrm{L}[34]\end{array}$ \\
\hline & & & Public transport: & Buses, coaches and taxis \\
\hline & & & ENVIMAT & $0.8 \mathrm{~kg} / €$, rail transport \\
\hline & & & The rest, EIO-LCA & $0.6 \mathrm{~kg} / €[35]$ \\
\hline Tangible goods & Consumer survey 2006 & 5,930 & EIO-LCA & \\
\hline Services & Consumer survey 2006 & 4,140 & EIO-LCA & \\
\hline $\begin{array}{l}\text { Air, maritime and } \\
\text { package travel }\end{array}$ & Consumer survey 2006 & 1,370 & EIO-LCA & \\
\hline Total & & 16,260 & & \\
\hline
\end{tabular}

\subsection{The Construction Phase GHG Assessment}

The construction phase emissions were assessed with a model employing a hybrid LCA method as well. The model also utilizes the EIO-LCA matrices due to the lower aggregation level of the model compared to other available IO models. To fit the model to a Finnish context, the same PPP correction as used in the use phase model was applied [30].

The land developer company supplied the input data, aggregated to 21 cost categories including both the buildings and infrastructure. These were matched with the EIO-LCA output matrices to create a rough picture of the emissions related to the construction phase. In the final model, the EIO-LCA basis was maintained to achieve high coverage of higher order production chain emissions, but local data was utilized to achieve better accuracy. Local data is employed for the three most significant categories, namely energy, concrete, and steel, which cover approximately $25 \%$ of the overall emissions. The method of incorporating the local emissions is slightly different than with the use phase assessment model described above. Concerning energy, the same tiered hybrid method was utilized (the combustion phase emissions of the local power plant [33]), but with concrete and steel products the whole EIO-LCA sectors were replaced with Finnish process LCA based emissions, as the production and delivery chains of these were assumed to be predominantly domestic. The life cycle emissions related to concrete and steel products were taken from the data published by the Building Information Foundation RTS [36]. 
Table 4 presents the input volumes and the data sources and scopes for the outputs, that is, the GHG emissions. The distribution of the construction costs in 21 categories, all the EIO-LCA sector choices, and discussion on the potential asymmetries can be found in Heinonen et al. [16] and Säynäjoki et al. [17].

Table 4. The input data sources, estimated costs, output data sources, and the carbon emissions of the construction of the buildings and the infrastructure.

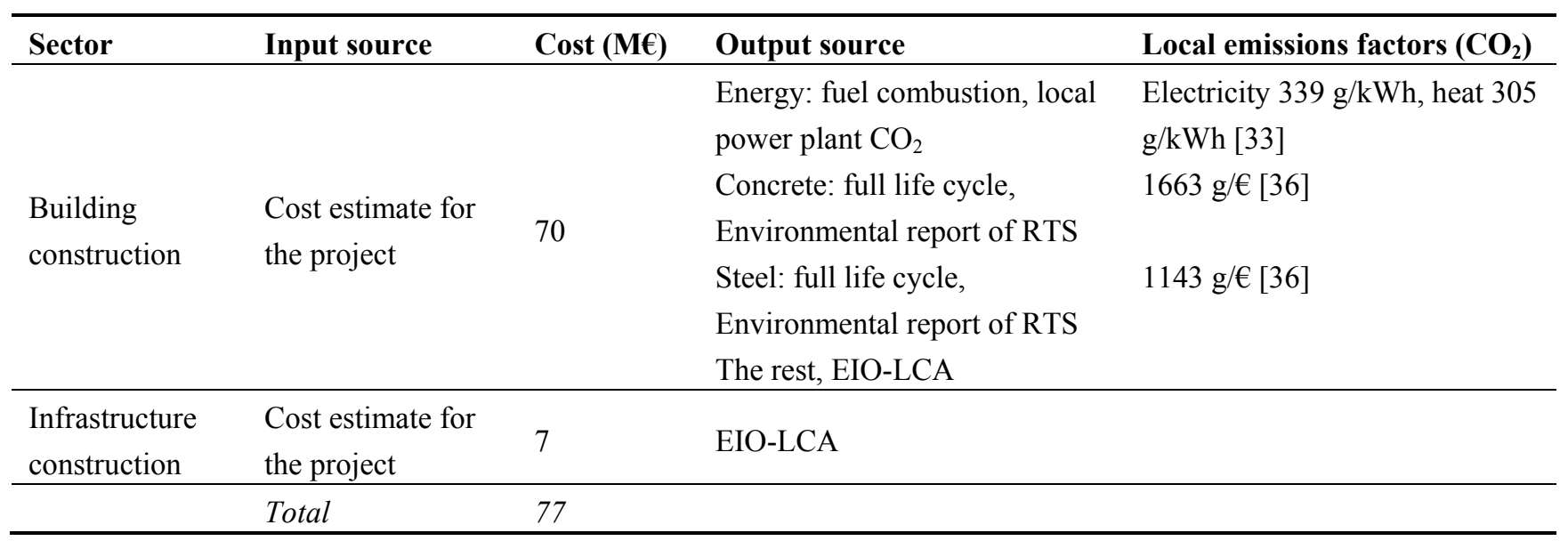

\section{The GHGs in a City Level Assessment and in a New Residential Development Assessment}

In this section, the GHGs of the residential area over the lifespan of the first 25 years are presented conjointly with the result from an assessment of the annual emissions of the profile resident on a city scale. At the end of the section the emission sources are analyzed in more detail.

\subsection{The Annual Emissions in the City and Residential Area Scopes}

In Figure 1 $(a, b)$ the emissions caused by the profile resident are presented. In Figure 1a the scope is the city level, where only a fraction of the construction activity taking place within the city is allocated to the average consumer and where he or she lives in an otherwise similar residence but with the average energy efficiency of the residential building stock in the city of Espoo. The profile resident's annual GHG emissions are slightly over $19 \mathrm{t}$ of $\mathrm{CO}_{2}$ equivalents $\left(\mathrm{t}^{\left.\mathrm{CO}_{2} \mathrm{e}\right)}\right.$ in a city level assessment. Housing dominates the emissions with a share of $6.4 \mathrm{t} \mathrm{CO}_{2} \mathrm{e}$. Within housing, the largest contributor is energy with $5.4 \mathrm{t}$. The share of construction is $2.6 \mathrm{t}$, a significant figure in this case due to the very high level of affluence of the consumer type in question, but still only less than $15 \%$ of the overall emissions.

Based on this dominance of energy related emissions in this type of city-level assessment, it would seem that concentrating on reducing these by increasing the building energy efficiency would be an efficient GHG mitigation policy. However, the construction phase emissions are often totally omitted, or if assessed on a city-level as above, they may describe incompletely the true impact of new construction since the building stock renews gradually. Next, the significant impact of this choice of perspective is demonstrated. 
Figure 1. (a) The annual carbon footprint of the profile resident in a city-level assessment; (b) The cumulative carbon emissions of the profile resident during the first 25 years of the new residential area.

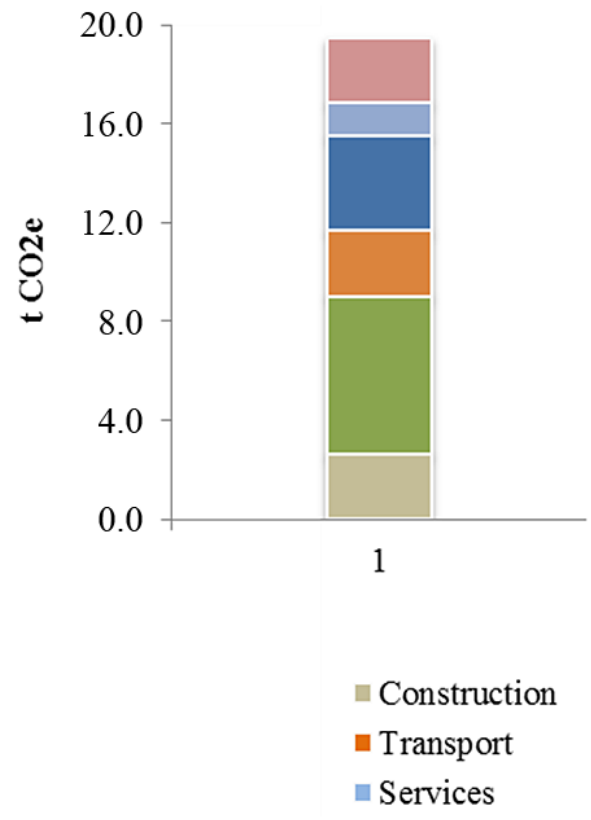

(a)

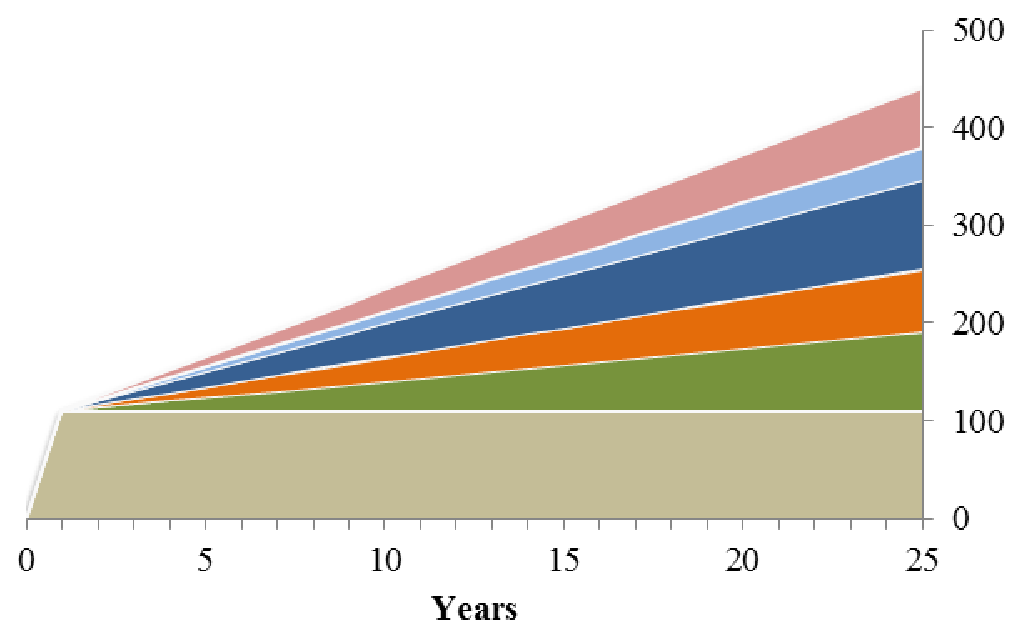

- Housing

- Tangible goods

$\square$ Air, maritime and package travel

(b)

In Figure $1 \mathrm{~b}$ the scope has been narrowed down to the level of the case residential area. Now, with the construction phase emissions being his/her share of the real emissions of the construction of the area, and with the energy efficiency of the buildings of the case area taken into account, the result is very different. The annual consumption based GHGs of the profile resident during the use phase is reduced to approximately $13.8 \mathrm{t} \mathrm{CO}_{2} \mathrm{e}$. The share of energy is only $2.4 \mathrm{t}$ due to the $55 \%$ improvement in the building energy efficiency compared to the city average. However, moving to a new residence causes a very large sudden spike in the carbon consumption of a resident when the construction phase emissions of the new residence and the infrastructure needed are allocated to the residents. This spike is either missing or incompletely reflected in the city-level assessments.

The overall construction phase emissions for the area are estimated at $60.900 \mathrm{t} \mathrm{CO}_{2} \mathrm{e}$, of which $92 \%$ is related to the buildings and $8 \%$ to the infrastructure. Allocated to the expected 550 residents, this amounts to approximately $110 \mathrm{t}$ per person, over eight times the annual use phase emissions. When the use phase emissions accumulate rather slowly, at the pace of $13.8 \mathrm{t}$ annually, the construction carbon spike actually dominates over a rather long time, as Figure $1 \mathrm{~b}$ shows. In the illustration of the 25 -year lifespan in Figure 1b, the share of the average resident of the construction phase emissions is allocated to year one, after which the emissions remain in the atmosphere (as illustrated by the gray area in Figure 1b). From year one the annual use phase emissions accumulate yearly with a steady phase (the simplistic assumption is discussed further below). The annual emissions are presented following the division into five broad sectors to demonstrate the impact of different types of consumption.

Analyzing further the results depicted in Figure 1(a,b), it can be seen that during the 25-year life cycle the profile resident of the new residential area is accountable for approximately $440 \mathrm{t} \mathrm{CO}_{2} \mathrm{e} \mathrm{GHG}$ emissions. The share of the construction phase spike is almost $25 \%$. If the comparison concerned only 
emissions directly related to residence, i.e., the categories Construction and Housing, the share would be as high as $60 \%$. This demonstrates that the impact of the construction phase emissions, when the temporal allocation is included, may be substantially higher than argued in many previous studies [37].

Very interestingly, in these premises the carbon payback time for the construction phase emissions is over 20 years. The overall emissions of the residents in the case area remain higher than those caused by the average terraced, detached or semi-detached house resident in Espoo until about 2035. Thus, the improvement in the building energy efficiency only contributes to climate change mitigation after 20 years, which is much later than 2020 - the peaking year target from IPCC [1] mentioned in the introduction. This stresses the importance of extending the focus of effective carbon management to include the construction phase emissions. Furthermore, assuming a continuous $1 \%$ renewal rate for the existing residential building stock, as has been the case in Finland, the overall cumulative emissions of the building stock actually only increase until the actual target year 2050, due to the construction phase emissions, despite the energy efficiency of the new buildings.

Next we added future scenarios for the decreases in the emissions from energy use and private driving to demonstrate the impacts of two of the most important near future developments on the assessment results. Concerning energy production, approximated from the recent scenario of Finnish Energy Industries [38], the GHG intensity of energy production is presumed decrease linearly by roughly $40 \%$ during the next 25 years. This development taken into account, the overall life cycle emissions caused by the average resident fall from the $440 \mathrm{t}$ of the base case down to $430 \mathrm{t}$, i.e., by approximately $10 \mathrm{t}$. In Housing only the emissions would decrease by $15 \%$. In private driving the emissions will also decrease as older cars are replaced by ones with improved fuel efficiency, as well as via improvements in the fuels themselves. For these improvements we utilized an approximation from the scenario from Helsinki Region Transport System (HLJ 2011), according to which the emissions from private driving fuel combustion will decrease by slightly over $50 \%$ during the next 25 years [39]. This development would cut an additional $15 \mathrm{t}$ of $\mathrm{CO}_{2} \mathrm{e}$ from the 25 -year cumulative emissions of the average resident, down to $415 \mathrm{t}$ in overall. Within Transportation the emissions would fall by nearly $25 \%$ according to this scenario. Taken that both scenarios would take place, the significance of the carbon spike from construction would increase further. The limitations of the presented scenario assessments are discussed in Discussion section.

\subsection{The Distribution of the GHG Emissions}

To gain an understanding of the role of different emission sources, as well as to give more perspective on the building related emissions, the emissions presented above are analyzed further in this section. Now, when the most important contributors to carbon consumption are looked at in more detail, some interesting findings emerge regarding both the construction and use phases. Regarding the construction phase, the largest source of GHGs is concrete with a share of 10\% (6100 $t$ ), followed by energy with 8\% (4600 t) and brickwork with 7\% (4400 t). Steel and wood structures both contribute a share of $6 \%(3600 \mathrm{t})$ and the remaining categories have shares of substantially less than $5 \%$ each. However, due to the lack of information on the subcontractors' work, $26 \%$ of the overall emissions, including subcontracting and on-site work, are assessed as general residential construction. Disaggregation of this share would somewhat increase the shares of the largest sectors mentioned above and increase the 
accuracy of the assessment. Notwithstanding, the distribution of the emissions is very wide. After the 20 largest emissions sources, 23\% still remain as "Others". This situation demonstrates how major reductions in the construction phase emissions would probably require radical changes in the materials throughout the current selection. The 10 most significant sectors are shown in Table 5.

Table 5. The 10 construction categories producing the largest carbon emissions $\left(\mathrm{t}_{2} \mathrm{e} /\right.$ capita).

\begin{tabular}{lcc}
\hline Material or function & City level (t $\left.\mathbf{C O}_{\mathbf{2}} \mathbf{e} / \mathbf{a} / \mathbf{c a p}.\right)$ & Case (t $\mathbf{C O}_{\mathbf{2}} \mathbf{e} / \mathbf{a} / \mathbf{c a p}$.) \\
\hline Overall & 2.6 & 110 \\
Subcontracting and on-site work & 28.7 \\
Concrete & 11.1 \\
Energy & 8.4 \\
Brickwork (bricks + plaster) & 8.0 \\
Steel & 6.5 \\
Wood structures & 6.5 \\
Components of water supply and sewage & 3.6 \\
HVAC material & 2.7 \\
Doors and windows & 2.0 \\
Water insulation & 1.2 \\
Other & 31.8 \\
\hline
\end{tabular}

During the use phase, even with the increased energy efficiency of the buildings, housing energy remains the largest single sector with $2.4 \mathrm{t} \mathrm{CO}_{2} \mathrm{e}$. Interestingly, largely due to the feature of the terraced, detached and semi-detached house residents in Espoo being the very affluent families of a generally affluent city and having easy access to an airport, the second largest contributor to the carbon consumption of the profile resident is package travel (dominated by flights abroad), with a share of $2.3 \mathrm{t}$. Also heavily related to the affluent lifestyle in large apartments and loose city structures, this is followed by private driving fuel combustion with a $1.9 \mathrm{t}$ share. Meat and dairy products come next with $1.4 \mathrm{t}$. The remaining sectors, which number over 50 , each contribute with shares of significantly less than 1.0 t. Table 6 gathers the 10 largest GHG contributors of the carbon load caused by the profile resident.

Table 6. The 10 largest GHG emissions producing categories.

\begin{tabular}{lc}
\hline Consumption category & Profile resident $\left(\mathbf{t ~} \mathbf{C O}_{\mathbf{2}} \mathbf{e} / \mathbf{a} / \mathbf{c a p}\right.$.) \\
\hline Overall & 13.8 \\
Housing energy & 2.4 \\
Package travel & 2.3 \\
Private driving fuel & 1.9 \\
Meat and dairy & 1.4 \\
Other food products and beverages & 0.7 \\
Clothes & 0.7 \\
Hotels, restaurants and cafés & 0.5 \\
Car acquisition & 0.5 \\
Sports and recreation equipment & 0.3 \\
Culture and recreation services & 0.3 \\
Other & 2.8 \\
\hline
\end{tabular}


When interpreting Table 6, it is obvious that the overall carbon consumption consists of a variety of small sources; this is even more so in the case of a new residential area with energy efficient buildings. This observation aggravates the attempts to find ways to decrease significantly the use phase emissions during the use phase and increases the importance of the planning and construction phase decisions.

\section{Representativeness of the Case}

We argued earlier in the paper that the phenomenon brought up in the study would also occur more generally around the world, which substantially increases the importance of understanding the implications of the situation. As Table 7 depicts, according to the data published by the International Energy Agency (IEA) [40], the broader existence of the phenomenon seems indeed true according to multiple indicators. First, the power generation carbon intensity of the power utilized in the case calculations complies fairly well with those of the EU-27 and with Russia, the USA and the UK having slightly worse profiles. Second, the share of residential building energy of all emissions is similar in each region. These together indicate similar, very long carbon payback times for new construction in all the regions.

Table 7. Indicators supporting broader global representativeness of the case area (data from IEA [40]).

\begin{tabular}{lcccccc}
\hline \multicolumn{1}{c}{ Indicator } & Case area & Finland & UK & EU-27 & USA & Russia \\
\hline $\begin{array}{l}\text { Power generation carbon intensities } \\
\left(\mathrm{g} \mathrm{CO}_{2} / \mathrm{kWh}\right)\end{array}$ & appox. 300 [23] & 205 & 450 & 339 & 531 & 317 \\
$\mathrm{CO}_{2}$ from residential building stock & - & $18.5 \%$ & $28.5 \%$ & $23.5 \%$ & $21.2 \%$ & $24.1 \%$ \\
energy use (2009) & - & $-28.9 \%$ & $-41.8 \%$ & $-37.0 \%$ & $-33.6 \%$ & $-31.7 \%$ \\
$\mathrm{CO}_{2} / \mathrm{GDP}$, change from 1990 to 2009 & - & $-5.6 \%$ & $-21.4 \%$ & $-16.6 \%$ & $-13.2 \%$ & $-26.6 \%$ \\
$\mathrm{CO}_{2} /$ capita, change from 1990 to 2009 & - & & & &
\end{tabular}

Furthermore, as Table 7 depicts, while the $\mathrm{CO}_{2}$ content of consumption $\left(\mathrm{g} \mathrm{CO}_{2} / \$\right)$ has decreased significantly in all the regions $(29 \%$ to $42 \%)$ in the last 20 years, the $\mathrm{CO}_{2}$ per capita has decreased much less ( $6 \%$ to $27 \%$ ). This means that the consumption volumes have increased substantially, which reduces the mitigation potential related to building energy efficiency.

It is worth noticing, however, that both the power generation carbon intensity and the share of building energy related $\mathrm{CO}_{2}$ emissions are the lowest in Finland, which may indicate that an increase in the building energy efficiency would be more effective in other regions. However, the emissions of the power plant of the case area are well above those in Finland on average, increasing the global representativeness of the case area. In any case, in each of the regions the carbon payback times are definitely long and, very importantly, emissions related to imports do not appear in the figures. These might significantly decrease the share of building energy in open and affluent economies [41,42].

\section{Discussion}

The study was set to analyze the concept of the construction of new low-carbon neighborhoods as an instrument of climate change mitigation in the built environment. A case study of a new residential development in the HMA in Finland was utilized to demonstrate the impacts occurring throughout the 
developed world. The argument of the study is that the neighborhood level emissions, especially related to new residential developments, are currently incompletely understood due to the prevailing belief that the construction phase emissions would have only minor relevance in the life cycle emissions of residential properties.

A hybrid LCA approach was employed, distinguishing the construction and use phases as well as taking into account the temporal allocation of the emissions over time. This fills the requirements of even a broad understanding of the WRI Scope 3 definition [28], which is important in measuring the emissions on a neighborhood level since there are few emissions taking place inside the neighborhood. Further, we argue that it is only with the type of approach presented here that the implications of new residential construction can be truly analyzed and effective carbon management in urban areas can emerge, and the results of the study strongly support this argument.

The study found that the construction phase, when allocating the emissions to the future residents, creates a carbon load of over eight times that caused annually by all consumption of the residents-approximately $110 \mathrm{t} \mathrm{CO}_{2} \mathrm{e}$ compared to $13.8 \mathrm{t}$. Moreover, compared to the annual energy use related emissions, $2.4 \mathrm{t}$, the construction phase emissions are in an overwhelmingly dominant position when a single residential development is regarded. The study also highlighted that even with rather energy efficient buildings the emissions of the new area remain as high as those of an average resident in an existing house during the selected 25-year lifespan. This stresses the importance of both including the temporal allocation perspective into the neighborhood level GHG assessments and reducing the construction phase emissions if new construction is to be used for climate change mitigation. Furthermore, if the construction phase emissions remain at the current level, the Finnish average $1 \%$ annual renewal rate leads only to an increase in the cumulative emissions up to 2050 , the current target year of significant mitigation needs.

By including the full consumption-based carbon footprint of the residents into the assessment, we were able to give context for the housing related emissions and the role of urban development in city-level decision-making. Actually, the traditional geographically restricted production-based approaches may fail to produce accurate information about the emissions even at a national or city level [43], let alone at a neighborhood level where there is presumably very little or no production. Thus, these type of consumption-based approaches could provide a very valuable complement to the production-based assessments.

When considering the representativeness of the study, there are two perspectives that should be covered. It is likely that a very similar situation with the construction phase carbon spike also exists in developed countries elsewhere, due to construction technologies having only limited variations. The whole context presumably has significant similarities as well, especially in countries with similar energy production GHG intensities. Regarding this perspective, it would seem that the consequences of construction are the most severe in Finland with relatively clean power production (as was shown in Section 6), but the current development trend of decreasing energy production intensities and increasing consumption volumes [40] further unifies the areas. In addition, due to the decreasing energy production intensities, the importance of the later use phase emissions decrease even further. In open economies like Finland, where over $50 \%$ of the value of consumption goods are imported [32], the emissions actually accumulate globally, decreasing the impact of local decisions. Ortiz et al. have also concluded that energy consumption of use phase has been an issue, especially in European countries, indicating that, 
even without low-energy buildings, the construction phase may account for a much larger share of the total life cycle emissions in countries with a warmer climate than that of Europe [44].

In Finland, the CHP production method in all major cities gives an additional, interesting perspective on the implications of building energy efficiency. Since heat is also a side product of electricity production in CHP plants, decreasing heat consumption in buildings only affects the overall carbon emissions if electricity generation is reduced as well [45]. Electricity use, however, is predominantly controlled by the residents and cannot be affected very much by building characteristics in district heated buildings [46,47]. The implication is that reducing the energy production GHG intensity and electricity consumption should be the primary targets of the carbon reduction strategies in the built environment instead of energy efficient buildings. However, as new construction will be required to a significant extent in the near future, attention should be paid to the construction materials alongside building energy efficiency. Notwithstanding, the kind of analysis conducted in this study points out that when the life cycle emissions of all consumption are taken into account, significant reductions are not easily attained.

One additional perspective on the true effects of carbon mitigation through energy efficient buildings is the rebound effect. For example, Turner et al. demonstrate that the emissions may even increase when energy efficiency increases [48]. This is due to people spending the savings gained by higher energy efficiency. In the initial assessment we didn't assume the savings to be spent. However, if the annual amount saved on energy consumption would be fully spent, and if we assume the same carbon intensity as that of the overall consumption on average $\left(0.9 \mathrm{~kg} \mathrm{CO}_{2} \mathrm{e} / €\right)$, the result is an approximately $0.5 \mathrm{t}$ increase in the annual emissions. Since energy has the highest carbon intensity among all goods, this is not enough to offset the $3.0 \mathrm{t}$ reduction in emissions gained by energy efficient buildings, but still a noteworthy figure.

This type of rebound effect analysis is very uncertain however. There is no way of knowing how the money will be spent, or even what the actual saving truly is. It might well be that the saving on energy is actually invested in the residence and thus already included in the assessment (while still potentially having a rebound effect through increased construction phase emissions, if not invested in low-carbon construction materials, etc.). High investment in the residence may even reduce other forms of consumption. Notwithstanding, the rebound effect further increases the importance of decreasing the carbon intensity of energy production as the main mitigation strategy. With this, the largest single source of carbon emissions can be affected at the city level and no direct rebound effect exists.

There are certain identified limitations and deficiencies in the assessment presented here. One limitation is the scope, including only one case study. This means that the assessment may be sensitive to changes in e.g., construction materials and material replacement rates. Regarding the material choices, the results are not highly sensitive to any single material change, as even the three largest GHG contributors, concrete, bricks and steel, which could to some extent be replaced by wood-based products, together account for less than $25 \%$ of the construction phase emissions. This result is supported by a building LCA sensitivity study of Junnila and Horvath who report rather low sensitivity of LCA results to emissions from construction materials [49]. Concerning the material replacement rates, Junnila and Horvath discuss that LCA's may underestimate real replacement rates during the building life cycle. In this study the replacement is approximated by the annual average money spent on maintenance, repairs and refurbishments by the projected future resident (under Housing). The 
amount is based on real monetary consumption data (the input data, see Sections 3 and 4), and should thus not lead to heavy underestimation of the replacement rates.

Second problem relates to the future uncertainties. While the temporal allocation of the emissions is taken into account, no changes in the emissions intensities or the consumption volumes are assumed, except for energy and fuel combustion emissions, which is unrealistic. However, these are also very difficult to predict. The intensities probably decrease over time as new technologies emerge, but the scale of the change is unclear. On the other hand, the consumption volume probably keeps increasing, causing the opposite effect on the carbon emissions that may easily offset the gains from the decreasing GHG intensities. Concerning the scenarios that were brought to the assessment, there are certain important limitations. While it is probable that energy production GHG intensities will fall within the next 25 years, the development is not necessarily similar in certain power plant (nor is the development predicted by the utilized scenario the only prediction available). The scenario utilized in the study presumes linear decrease in the GHG intensity, but in a single power plant the development would likely be in leaps after rather steady periods. It is also possible that the particular power plant utilized in the study will not undergo significant changes during the next 25 years. However, the perspective given by the scenario adds to the generalizability of the results to different urban developments in different locations and moments in time. The fuel combustion scenario may also either under- or overestimate the future change, but suffers less from the above described problem caused by the neighborhood perspective. Furthermore, there is actually a negative discount factor for the near future emissions [50]. $\mathrm{CO}_{2}$ persists in the atmosphere for a long time, and the accumulation of the emissions is in fact the key problem instead of the annual magnitudes. Adding this perspective to the analysis should be one important objective of future research.

A second deficiency is that the projected resident's consumption profile may deviate from the true consumption of the future residents significantly. Different areas and building types attract different kinds of residents. For example, in Espoo the average detached house resident is very affluent and consumes much more than city residents living in apartments [20]. The income level is almost twice the income of an apartment resident and the consumption volume approximately $25 \%$ higher. However, reducing the carbon emissions by attracting less affluent residents would not affect the GHGs from a wider perspective, as the more affluent would just reside somewhere else. Notwithstanding, both Majamaa et al. [19] and the area qualities suggest that the profile resident is fairly representative of the future residents.

Finally, the assessments are subject to a number of uncertainties that decrease the accuracy of the results. These uncertainties are discussed in detail in Heinonen and Junnila [21-23] and in Heinonen et al. [16,24] with the conclusion that they should not compromise the overall findings as long as the aggregate level of the average residents is maintained in the analyses.

For positioning the study among academic research in the field, not many similar approaches could be identified. However, the different perspectives of the study arise from the earlier contributions of many academics. Firstly, it is very well understood in general that rapid urbanization in developing countries is a huge challenge for global GHG mitigation efforts. This is partly due to the increasing consumption of goods and services, but as Minx et al. recently showed in a case study in China, increasing GHG emissions there are largely due to intensive construction activity taking place in cities [51]. An increase in the importance of the construction phase emissions also relates partly to the 
assessment methods; e.g., Toller et al. argue for the importance of taking into account the emissions embedded in construction materials in GHG mitigation strategies [52] that an IO based LCA can capture, but which may be left outside of the boundary of process LCAs.

Concerning the planning perspective, Wallbaum et al. bring up the incompleteness of the sustainability assessment methods when city planning is concerned [53]. Further, they stress the importance of incorporating the environmental perspectives into the early phase planning. The different significance of the emissions occurring now and in the near future, compared to those taking place later, has been recently stated by e.g., Levasseur et al. [54] and Dutil et al. [55]. Schwietzke et al. analyze corn ethanol production with a temporal model, arguing for a higher priority for reducing the early phase emissions [50] - a situation very similar to buildings from the GHG emissions perspective.

Moreover, many authors have brought up the utility of the consumption perspective on emissions, especially when city-level assessments are concerned, one of the key arguments being that on a local level the consumption perspective is needed to capture the real GHG impacts of the local society $[3,6,43,56,57]$. This argument seems to be stronger and stronger the smaller the concerned area is. With a different perspective and scope on the assessed emissions, the case area presented in this study could seem to cause very little emissions and be of little importance to city-level GHG mitigation. Additionally, as Peters and Hertwich argue, and as can also be concluded from the results of this study, more sustainable consumption habits need to be promoted in order to achieve significant GHG reductions [58]. This calls for local level consumption-based assessment techniques. Jones and Kammen recently compared different consumption choices from just this perspective [59]. According to VandeWeghe and Kennedy, the consumption perspective also enables meaningful conclusions for urban planning [60]. Larsen and Hertwich have developed a local assessment model for Trondheim, Norway using a similar argument; that a consumption-based model would provide better information for local action [61]. Other local assessment approaches in recent years include e.g., Erickson et al., Baynes et al. and Lenzen et al. [43,62,63]. Satterthwaite further discusses the significance of the allocation perspective of the emissions on the assessment results, which highlight the problematic situation of current city level GHG assessment methods [64]. Finally, systems thinking and industrial ecology, albeit being less structured approaches, provide similar ideas in suggesting to adopt a wide WRI scope 3 type of perspective in the assessments [65].

To conclude, the contribution of the paper is primarily attached to two findings. First and foremost, without a significant reduction in the construction phase emissions in the very near future, new residential construction cannot be utilized as an instrument of climate change mitigation in the built environment. According to the study, new construction seems to have a detrimental impact, even on the 2050 reduction targets. Second, the paper presents a framework to assess, understand, and manage GHG emissions on a neighborhood level. Since several indicators implied the phenomenon to occur around the world, the presented case study may serve as an important basis for further development in the future.

\section{References}

1. The Core Writing Team; Pachauri, R.K.; Reisinger, A. IPCC, 2007: Climate Change 2007: Synthesis Report. Contribution of Working Groups I, II and III to the Fourth Assessment Report of the Intergovernmental Panel on Climate; IPCC: Geneva, Switzerland, 2007; pp. 1-104. 
2. City Planning Will Determine Pace of Global Warming, Un-Habitat Chief Tells Second Committee as She Links Urban Poverty with Climate Change; Department of Public Information, United Nations: New York, NY, USA, 30 October 2007. Available online: http:/www.un.org/ News/Press/docs/2007/gaef3190.doc.htm (accessed on 7 April 2011).

3. Ramaswami, A.; Hillman, T.; Janson, B.; Reiner, M.; Thomas, G. A demand-centered, hybrid life-cycle methodology for city-scale greenhouse gas inventories. Environ. Sci. Technol. 2008, 42, 6455-6461.

4. Kennedy, C.; Steinberger, J.; Gasson, B.; Hansen, Y.; Hillman, T.; Havránek, M.; Pataki, D.; Phdungsilp, A.; Ramaswami, A.; Villalba Mendez, G. Greenhouse gas emissions from global cities. Environ. Sci. Technol. 2009, 43, 7297-7302.

5. Heinonen, J. The Impacts of Urban Structure and the Related Consumption Patterns on the Carbon Emissions of an Average Consumer. Ph.D. Thesis, Aalto University, Helsinki, Finland, 2012.

6. Schulz, N. Delving into the carbon footprints of Singapore-Comparing direct and indirect greenhouse gas emissions of a small and open economic system. Energy Policy 2007, 38, 4848-4855.

7. Fong, W.-K; Matsumoto, H.; Lun, Y.-F. Application of System Dynamics model as decision making tool in urban planning process toward stabilizing carbon dioxide emissions from cities. Build. Environ. 2009, 44, 1528-1537.

8. Environmental Report of the City of Helsinki 2010; The City of Helsinki Administration Centre: Helsinki, Finland, 2011.

9. Long-Term Climate and Energy Strategy; Reports of the Ministry of the Environment 19/2008; Ministry of the Environment: Helsinki, Finland, 2008.

10. The National Building Code of Finland. Ministry of the Environment Homepage. Available online: http://www.ymparisto.fi/default.asp?node=12055\&lan=en (accessed on 7 November 2011).

11. García-Casals, X. Analysis of building energy regulation and certification in Europe: Their role, limitations and differences. Energy Build. 2006, 38, 381-392.

12. Nemry, F.; Uihlein, A.; Colodel, C.M.; Wetzel, C.; Braune, A.; Wittstock, B.; Hasan, I.; Kreissig, J.; Gallon, N.; Niemeier, S.; Frech, Y. Options to reduce the environmental impacts of residential buildings in the European Union: Potential and costs. Energy Build. 2010, 42, 976-984.

13. Junnila, S.; Horvath, A.; Guggemos, A.A. Life-cycle assessment of office buildings in Europe and the United States. J. Infrastruct. Syst. 2006, 12, 10-17.

14. Sartori, I.; Hestnes, A.G. Energy use in the life cycle of conventional and low-energy buildings: A review article. Energy Build. 2007, 39, 249-257.

15. Gustavsson, L.; Joelsson, A. Life cycle primary energy analysis of residential buildings. Energy Build. 2010, 42, 210-220.

16. Heinonen, J.; Säynäjoki, A.; Junnila, S. A longitudinal study on the carbon emissions of a new residential development. Sustainability 2011, 3, 1170-1189.

17. Säynäjoki, A.; Heinonen, J.; Junnila, S. Carbon footprint assessment of a residential development project. Int. J. Environ. Sci. Dev. 2011, 2, 116-123.

18. Kiiras, J.; Saari, A.; Hyart, J.; Kammonen, J. Property Maintenance Expenses in Finland 1992 (Kiinteistöjen Ylläpidon Kustannustieto 1992); Helsinki University of Technology: Helsinki, Finland, 1993. 
19. Majamaa, W.; Kuronen, M.; Heywood, C.; Kostiainen, J. A consumer-oriented technique for planned residential developments. Int. J. Hous. Mark. Anal. 2008, 1, 231-245.

20. Official Statistics of Finland (OSF). Consumer Survey [e-Publication]; Statistics Finland: Helsinki, Finland; ISSN=1799-1382. Available online: http://stat.fi/til/kbar/tau_en.html (only partly publicly available) (accessed on 3 November 2011).

21. Heinonen, J.; Junnila, S. Case study on the carbon consumption of two metropolitan cities. Int. J. Life Cycle Assess. 2011, 16, 569-579.

22. Heinonen, J.; Junnila, S. Implications of urban structure on carbon consumption in metropolitan areas. Environ. Res. Lett. 2011, 6, doi:10.1088/1748-9326/6/1/014018.

23. Heinonen, J.; Junnila, S. A carbon consumption comparison of rural and urban lifestyles. Sustainability 2011, 3, 1234-1249.

24. Heinonen, J.; Kyrö, R.; Junnila, S. Dense downtown living more carbon intense due to higher consumption: A case study of Helsinki. Environ. Res. Lett. 2011, 6, doi:10.1088/17489326/6/3/034034.

25. Crawford, R. Life Cycle Assessment in the Built Environment; Spon Press: London, UK, 2011.

26. Suh, S.; Lenzen, M.; Treloar, G.J.; Hondo, H.; Horvath, A.; Huppes, G.; Jolliet, O.; Klann, U.; Krewitt, W.; Moriguchi, Y.; et al. System boundary selection in life-cycle inventories using hybrid approaches. Environ. Sci. Technol. 2004, 38, 657-664.

27. Economic Input-Output Life Cycle Assessment (EIO-LCA), US 2002 Industry Benchmark Model; Carnegie Mellon University Green Design Institute: Pittsburgh, PA, USA, 2008. Available online: http://www.eiolca.net/ (accessed on 1 February 2010).

28. World Resources Institute: Greenhouse Gas Protocol Initiative. New Guidelines for Product and Supply Chain Accounting and Reporting; World Business Council for Sustainable Development: Geneva, Switzerland, 2009.

29. Lenzen, M.; Pade, L.-L; Munksgaard, J. $\mathrm{CO}_{2}$ multipliers in multi-region input-output models. Econ. Syst. Res. 2004, 16, 391-412.

30. Global Purchasing Power Parities and Real Expenditures; 2005 International Comparison Program, The World Bank: Washington, DC, USA, 2008. Available online: http://siteresources.worldbank. org/ICPINT/Resources/icp-final.pdf (accessed on 18 September 2011).

31. Weber, C.L.; Matthews, H.S. Quantifying the global and distributional aspects of American household carbon footprint. Ecol. Econ. 2008, 66, 379-391.

32. Official Statistics of Finland (OSF). Income Distribution Statistics [e-Publication]; Statistics Finland: Helsinki, Finland; ISSN=1799-1331. Available online: http://stat.fi/til/tjt/index_en.html (accessed on 15 December 2009).

33. Production and fuels. Finnish Energy Industries Homepage. Available online: http://www.energia.fi/en/ (accessed on 20 January 2010).

34. Fuel combustion $\mathrm{CO}_{2}$ emissions. Motiva Oy [in Finnish]. Available online: http://motiva.fi/liikenne/polttoaineet_ja_ajoneuvotekniikka/polttoaineet (accessed on 7 June 2011). 
35. Seppälä, J.; Mäenpää, I.; Koskela, S.; Mattila, T.; Nissinen, A.; Katajajuuri, J.-M.; Härmä, T.; Korhonen, M.-R.; Saarinen, M.; Virtanen, Y. Assessment of The Environmental Impacts of Material Flows Caused by the Finnish Economy with the ENVIMAT Model (Suomen Kansantalouden Materiaalivirtojen Ympäristövaikutusten Arviointi ENVIMAT-Mallilla); Edita Prima Oy: Helsinki, Finland, 2009; Finnish Environment 20/2009.

36. The Building Information Foundation RTS: RT-Ympäristöseloste Homepage. Available online: http://www.rts.fi/ymparistoseloste/ (accessed on 20 July 2010).

37. Sharrard, A.; Matthews, H.; Ries, R. Estimating construction project environmental effects using an input-output-based hybrid life-cycle assessment model. J. Infrastruct. Syst. 2008, 14, 327-336.

38. Vanhanen, J.; Vehviläinen, I.; Halonen, M.; Kumpulainen, A. System Level Economic, Environmental and Societal Impacts of Energy Scenarios (Energiaskenaarioiden Järjestelmävaikutukset ja Niiden Taloudelliset, Ympäristölliset ja Yhteiskunnalliset Seuraukset); The Finnish Innovation Fund Sitra: Helsinki, Finland, 2010.

39. Nylund, N. Possibilities of Vehicle and Fuel Technology in Reducing Emissions from Car Traffic; YTV Helsinki Metropolitan Area Council: Helsinki, Finland, 2009.

40. OECD/IEA. $\mathrm{CO}_{2}$ Emissions from Fuel Combustion: Highlights; International Energy Agency (IEA): Paris, France. Available online: http://www.iea.org/co2highlights/co2highlights.pdf (accessed on 10 October 2011).

41. Turner, K.; Munday, M.; McGregor, P.; Swales, K. How Responsible is a Region for its Carbon Emissions? An Integrated Input-Output and CGE Analysis; Stirling Economics Discussion Paper 2011-06; Stirling Management School, University of Stirling: Stirling, UK, 2011. Available online: http://hdl.handle.net/1893/3004 (accessed on 10 October 2011).

42. Wagner, G. Energy content of world trade. Energy Policy 2010, 38, 7710-7721.

43. Erickson, P.; Allaway, D.; Lazarus, M.; Stanton, E.A. A consumption-based GHG inventory for the U.S. State of Oregon. Environ. Sci. Technol. 2012, 46, 3679-3686.

44. Ortiz, O.; Castells, A.; Sonnemann, G. Sustainability in the construction industry: A review of recent developments based on LCA. Constr. Build. Mater. 2009, 23, 28-39.

45. Kurnitski, J.; Keto, M. Emissions from Building Energy Consumption and Primary Energy Use in Finland (Rakennusten Energiankäytön Aiheuttamat Päästöt ja Primäärienergiankäyttö); Rakennustieto Oy: Helsinki, Finland, 2010.

46. Kyrö, R.; Heinonen, J.; Junnila, S. Occupants have little influence on the overall energy consumption in district heated apartment buildings. Energy Build. 2011, 43, 3484-3490.

47. Wright, A. What is the relationship between built form and energy use in dwellings? Energy Policy 2008, 36, 4544-4547.

48. Turner, K. Negative rebound and disinvestment effects in response to an improvement in energy efficiency in the UK economy. Energy Econ. 2009, 31, 648-666.

49. Junnila, S.; Horvath, A. Environmental sensitivity analysis of the life-cycle of an office building. In Proceedings of the ILCDES 2003: Integrated Lifetime Engineering of Buildings and Civil Infrastructures, Kuopio, Finland, 1-3 December 2003; In-House Publishing: Rotterdam, The Netherlands, 2003. Available online: http://www.irbnet.de/daten/iconda/CIB5426.pdf (accessed on 19 July 2012). 
50. Schwietzke, S.; Griffin, W.M.; Matthews, H.S. Relevance of emissions timing in biofuel greenhouse gases and climate impacts. Environ. Sci. Technol. 2011, 45, 8197-8203.

51. Minx, J.C.; Baiocchi, G.; Peters, G.P.; Weber, C.L.; Guan, D.; Hubacek, K. A “carbonizing dragon”: China's fast growing $\mathrm{CO}_{2}$ emissions revisited. Environ. Sci. Technol. 2011, 45, 9144-9153.

52. Toller, S.; Wadeskog, A.; Finnveden, G.; Malmqvist, T.; Carlsson, A. Energy use and environmental impacts of the real estate management sector. J. Ind. Ecol. 2011, 15, 394-404.

53. Wallbaum, H.; Krank, S.; Teloh, R. Prioritizing sustainability criteria in urban planning processes: Methodology application. J. Urban Plan. Dev. 2011, 3, 20-28.

54. Levasseur, A.; Lesage, P.; Margni, M.; Deschênes, L.; Samson, R. Considering time in LCA: Dynamic LCA and its application to global warming impact assessments. Environ. Sci. Technol. 2010, 44, 3169-3174.

55. Dutil, Y.; Rousse, D.; Quesada, G. Sustainable buildings: An ever evolving target. Sustainability 2011, 3, 443-464.

56. Sovacool, B.K.; Brown, M.A. Twelve metropolitan carbon footprints: A preliminary comparative global assessment. Energy Policy 2010, 38, 4856-4869.

57. Peters, G.; Solli, C. Global Carbon Footprints: Methods and Import/Export Corrected Results from the Nordic Countries in Global Carbon Footprint Studies; Nordic Council of Ministers: Copenhagen, Denmark, 2010; TemaNord 2010:592. Available online: http://www.norden.org/fi/ julkaisut/julkaisut/2010-592 (accessed on 19 June 2012).

58. Peters, G.P.; Hertwich, E.G. The importance of imports for household environmental impacts. J. Ind. Ecol. 2006, 10, 89-109.

59. Jones, C.M.; Kammen, D.M. Quantifying carbon footprint reduction opportunities for U.S. households and communities. Environ. Sci. Technol. 2011, 45, 4088-4095.

60. VandeWeghe, J.R.; Kennedy, C. A spatial analysis of residential greenhouse gas emissions in the Toronto Census Metropolitan area. J. Ind. Ecol. 2007, 11, 133-144.

61. Larsen, H.N.; Hertwich, E.G. The case for consumption-based accounting of greenhouse gas emissions to promote local climate action. Environ. Sci. Technol. 2009, 12, 791-798.

62. Baynes, T.; Lenzen, M.; Steinberger, J.K.; Bai, X. Comparison of household consumption and regional production approaches to assess urban energy use and implications for policy. Energy Policy 2011, 39, 7298-7309.

63. Lenzen, M.; Dey, C.; Foran, B. Energy requirements of Sydney households. Ecol. Econ. 2004, 49, 375-399.

64. Satterthwaite, D. Cities' contribution to global warming: Notes on the allocation of greenhouse gas emissions. Environ. Urban. 2008, 20, 539-549.

65. Kuronen, M.; Junnila, S.; Majamaa, W.; Niiranen, I. Public-private-people partnership as a way to reduce carbon dioxide emissions from residential development. Int. J. Strateg. Prop. Manag. 2010, 14, 200-216.

(C) 2012 by the authors; licensee MDPI, Basel, Switzerland. This article is an open access article distributed under the terms and conditions of the Creative Commons Attribution license (http://creativecommons.org/licenses/by/3.0/). 